\title{
Research on Evaluation and Driving Factors of Sustainable Development of Chinese Sub-Provincial Cities Based on Public Participation
}

\author{
Yidong Chang, Xiangchao Ji \\ Department of Geography and Urban-Rural Planning, School of Tourism and Geographical Sciences, Qingdao University, \\ Qingdao, China \\ Email: 874865293@qq.com
}

How to cite this paper: Chang, Y.D. and Ji, X.C. (2020) Research on Evaluation and Driving Factors of Sustainable Development of Chinese Sub-Provincial Cities Based on Public Participation. Open Access Library Journal, 7: e6571.

https://doi.org/10.4236/oalib.1106571

Received: July 2, 2020

Accepted: July 17, 2020

Published: July 20, 2020

Copyright $\odot 2020$ by author(s) and Open Access Library Inc.

This work is licensed under the Creative Commons Attribution International License (CC BY 4.0).

http://creativecommons.org/licenses/by/4.0/

(c) (i) Open Access

\begin{abstract}
The main body of this paper focuses on the status and planning of the sustainable construction of Chinese sub-provincial cities. Twelve evaluation indicators are selected through the three supporting subsystems of economy, society and environment, and weights are given according to the selected indicators. The city's sustainable development indicators for 15 sub-provincial cities from 2013 to 2017 and horizontal comparisons in various years (mainly 2017) are aimed at a reasonable ranking. The results of this study are as follows: 1) The final research results are more in line with the current state of economic construction in China's sub-provincial cities; 2) The gap between China's sub-provincial cities in sustainable development level is larger, Guangzhou and Shenzhen have higher overall levels. The overall level in Xi' an and Harbin is the weakest; 3 ) Since 2013, the sub-provincial cities have had a sustainable development level that first increased and then decreased, and the regional differences have gradually decreased; 4) The coefficient of variation helps us understand the different factors on the level of sustainable development. The impact of public ratings will help us understand the level of sustainable development from a public perspective.
\end{abstract}

\section{Subject Areas}

Development Economics

\section{Keywords}

Sustainability Level, China's Sub-Provincial Cities, Geographic Detectors, Coefficient of Variation, Public Participation 


\section{1. 引言}

1987 年 2 月, 联合国发展委员会发表了一篇名为《我们共同的未来》文 章, 主要内容就是社会群体共同关注的可持续发展战略—— “既能够在现在 得到发展, 同时也可以为未来的发展留有余地”。可持续发展的城市发展是 建立在一定程度的时间和空间上的, 目的是为了推动城市的长远持续性发展 进步, 促进发展结构的调整完善, 使经济、社会、环境协调发展, 最终实现 高度发达的城市化和现代化。1991 年, 国际生态学联合会(INECCOL)和国际 生物学联合会(IUBS)共同开展了以持续性发展为主体的交流研究会议, 这个 会议把可持续发展简单概括为 “保护和提高整体环境体制的生存发展能力”。

进入新世纪以来, 可持续发展在我国得到了空前的关注, 2003 年胡锦涛 总书记在党的十六大中提出可持续发展观, 后来习近平总书记提出 “金山银 山不如绿水青山”。自从形成持续性发展内容后, 中国的研究专家以及人民 群众都有着极高的关注度和考察分析实践, 牛振国教授认为, 可持续发展与 机理研究, 尺度问题, 区域整体关系研究需要进一步加强[1]。通过分析可持 续发展水平和能力的相关性, 可进一步解释不同城市因自然条件和经济社会 发展水平差异而导致的可持续发展差异[2] [3]。

笔者在研究可持续发展评价时发现现有科技论文的可持续评价体系基本 为理论方法评价体系, 刘志成等[4]利用生态足迹对城市的可持续发展能力评 价, 邓绵山等[5]利用能值对城市进行分析, 而综合整个学科研究来看, 例如 赵海云等[6], 周子英等[7], 李博等[8], 霍丽娜等[9]利用层次分析法分析数据 的研究数目偏多。对于层次分析法而言, 它使用专家打分进行权重的确定, 虽然专家打分科学性较强, 但很难反映民意。结合其他研究城市可持续发展 的方法来看, 目前国内基于公共视角的论文出品较少, 实践性偏弱, 为了更 好地反映民意, 笔者写作了基于公众参与的这篇文章, 同时希望本文章能为 后来研究主动视角的人提供相关经验。

\section{2. 研究区域}

研究区域为中国的 15 个副省级城市, 其中包括 5 个计划单列市(深圳、 大连、青岛、宁波、厦门)和 10 个省会城市(广州、南京、杭州、武汉、成都、 济南、西安、长春、沈阳、哈尔滨)。副省级城市虽然其本质是在行政架构上 为副省级建制的市, 但实际上各个城市无论在经济上、文化上、社会发展水 平上、政治地位上都是我国除直辖市外的最高水平, 代表着我国的发展水平。

为更好地认识中国副省级城市的可持续发展水平, 本文从经济、社会、 环境等与可持续发展密切相关的方面入手, 利用地理探测器和公众打分两种 方法确定可持续发展评价指标体系, 并选取十三五规划以来的 5 个时期: 2013 年、 2014 年、 2015 年、 2016 年、 2017 年, 对中国副省级城市的可持续发展 水平进行评价。

\section{3. 数据来源与方法}

\section{1. 数据来源}

研究中数据来源于《中国统计年鉴》 《中国城市统计年鉴》 《中国环境 
统计年鉴》以及各个副省级城市的 2013 2017 年的各个城市的统计公报和统 计年鉴。

研究中公众参与确定权重的数据来源于利用问卷星向公众发放的网络调 查问卷, 其中发放并收回共 300 份调查问卷, 调查问卷(见附录一)由笔者参考 许学强等[10]的论文, 篎选研究所需要的指标, 自主设计并发布, 由于我们目 标是研究城市可持续发展水平, 需要切实参与到城市建设的从业者或者是未 来参与城市建设中的从业者即在校生(这里的在校生我们指在读本科或本科 以上学历以及职业教育学生), 因此调查问卷范围设置从在校生到社会从业人 员, 参与调查的人员主要集中在 18 38 岁并且男女比例基本达到 1:1, 在校生 参与调查的较多, 达三分之二, 调查的样本符合信度与效度的指标(见附录二)。

\section{2. 研究方法}

\section{(1) max-min 归一化(离差标准化) [11]}

对于收集到的数据, 由于涉及到各城市经济社会环境的多方面的指标, 各指标的数据间存在数量级、单位的差异, 故首先需要对其进行无量纲化处 理。本次研究中采用 max-min 归一化, 又称离差标准化的方法对数据进行无 量纲化处理, 将每个指标的数值都转化为 0 到 1 之间(包括 0 和 1 ), 公式为:

$$
x_{i}^{\prime}=\frac{x_{i}-\min }{\max -\min }
$$

其中 $x_{i}$ 为转化前的某城市某个指标的数值, $x_{i}^{\prime}$ 为转化后的数值, 为表示上的 简便, 文章后面使用 $x_{i}$ 代替, $\min$ 为某指标中最小的值, $\max$ 为某指标中最 大的数值。

\section{(2) 变异系数法[12]}

可持续发展涉及的指标较多, 构成复杂, 在综合对比了变异系数法和熵 权法后，使用变异系数来确定各指标的权重，并以此作为根据数据本身的统 计属性确定权重类型的方法与公众参与打分确定的权重进行对比。变异系数 法确定的指标权重大小，取决于每个指标中各城市间差异的大小，城市间差 异越大的指标，其权重越大。其公式为:

$$
\begin{gathered}
V_{i}=\frac{\sigma_{i}}{\bar{x}_{i}} \quad(i=1,2, \cdots, n) \\
w_{i}=\frac{V_{i}}{\sum V_{i}} \quad(i=1,2, \cdots, n)
\end{gathered}
$$

其中, $\sigma_{i}$ 为该指标的标准差, $\bar{x}_{i}$ 为该指标的平均值, $V_{i}$ 为该指标的变异系数, $w_{i}$ 为该指标的权重。

\section{(3) 公众参与打分确定权重}

公众参与打分确定的权重由问卷中公众对每个指标所打的总分确定，其 公式为:

$$
w_{i}=\frac{G_{i}}{\sum G_{i}}
$$

其中, $G_{i}$ 为所有公众对该指标所评分的总和，即每个指标的权重为其总得分 
与所有指标的总得分之比。

\section{(4) 地理探测器的因子探测}

地理探测器是由王劲峰[13]提出, 最初应用于地方性疾病风险影响因素的 研究, 后被广泛运用与地理事物空间分布的形成机理研究。本次研究中使用 地理探测器中的因子探测, 量化地研究所选取的六个指标对可持续发展的影 响力大小。因子探测基于地理空间分异规律的原则创建, 使用前需要进行离 散化处理，最后得到 0 到 1 之间的一个结果，结果的数值越大，说明该指标 对可持续发展的影响力越大。因子探测的模型如下:

$$
q=1-\frac{1}{n \sigma^{2}} \sum_{i=1}^{m} n_{i} \sigma_{i}^{2}
$$

其中, $q$ 为该指标对可持续发展得分的影响力大小, $n$ 为总的城市数, $\sigma^{2}$ 为 该指标全部城市的方差, $n_{i}$ 为单个区域的城市数量, $\sigma_{i}^{2}$ 为该指标单个区域的 全部城市的方差。

\section{3. 可持续发展指标评价体系[10]}

在参考以往的其他研究文献的基础上，本次研究中将可持续发展的指标 评价体系分为两级，共采用三个一级指标和 12 个二级指标。其中，一级指标 分为经济发展水平、社会发展水平和环境发展水平三个方面, 每个方面下均 包含 4 个二级指标用以衡量其大小。指标评价体系如表 1 所示。

\section{4. 结果分析}

\section{1. 公众参与确定权重与变异系数法确定权重的对比分析}

如表 2 所示，这部分的公众打分在诸如人均地区生产总值、第三产业增 表 1. 可持续发展指标评价体系及权重

\begin{tabular}{|c|c|c|c|}
\hline 一级指标 & 二级指标 & 公众打分权重 & 变异系数法权重 \\
\hline 经 & 人均地区生产总值(元人民币) & 0.0828 & 0.0687 \\
\hline 发 & 第三产业增加值占生产总值的比重(\%) & 0.0790 & 0.0655 \\
\hline $\begin{array}{l}\text { 水 } \\
\text { 平 }\end{array}$ & 第二产业增加值占生产总值的比重(\%) & 0.0775 & 0.0569 \\
\hline 价 & 人均工业增加值(元) & 0.0760 & 0.0680 \\
\hline 社 & 全年城市居民可支配收入(元) & 0.0843 & 0.0787 \\
\hline 苃 & 居民消费水平(元) & 0.0851 & 0.0521 \\
\hline $\begin{array}{l}\text { 水 } \\
\text { 平 }\end{array}$ & 全市新增就业(万人) & 0.0843 & 0.2339 \\
\hline 论 & 图书馆藏书量(千册) & 0.0722 & 0.0733 \\
\hline 环 & 市辖区绿地面积 $\left(\mathrm{km}^{2}\right)$ & 0.0866 & 0.1671 \\
\hline 发 & 环境空气质量达标天数 & 0.0927 & 0.0524 \\
\hline $\begin{array}{l}\text { 水 } \\
\text { 平 }\end{array}$ & 全市污水处理率(\%) & 0.0904 & 0.0375 \\
\hline $\begin{array}{l}\text { 评 } \\
\text { 价 }\end{array}$ & 全市垃圾无害化处理率(\%) & 0.0889 & 0.0458 \\
\hline
\end{tabular}


表 2. 公众参与确定权重与变异系数法确定权重对比

\begin{tabular}{ccc}
\hline 权重 & 公众打分 & 变异系数均值 \\
\hline 人均地区生产总值/元 & 0.082827 & 0.081616 \\
第三产业增加值占生产总值的比重 $/ \%$ & 0.079027 & 0.06572 \\
第二产业增加值占生产总值的比重/\% & 0.077508 & 0.06765 \\
人均工业增加值/元 & 0.075988 & 0.079757 \\
全年城市居民人均可支配收入/元 & 0.084347 & 0.080391 \\
居民消费水平/元 & 0.085106 & 0.064461 \\
全市城镇新增就业/万人 & 0.084347 & 0.120977 \\
图书馆藏书量/千册 & 0.075188 & 0.114229 \\
市辖区绿地面积 $/ \mathrm{khm}^{2}$ & 0.086626 & 0.176613 \\
环境空气质量达标天数 $/ \%$ & 0.092705 & 0.061823 \\
全市城市污水集中处理率 $/ \%$ & 0.090426 & 0.040176 \\
全市垃圾无害化处理率 $/ \%$ & 0.088906 & 0.046587 \\
\hline
\end{tabular}

加值占生产总值的比重等经济指标方面评分的权重要比变异系数确定的权重 要高, 而在市区绿地面积、图书馆藏书量等方面变异系数的打分要比公众打 分要高, 说明在公众视角下, 经济因素要比环境因素重要的多, 而经过地理 探测器判断, 实际上环境因素其实在城市的可持续发展评价体系中占有重要 地位。

\subsection{1. 可持续发展的副省级城市间差异分析}

如图 1、图 2 所示, 无论是在公众视角还是变异系数确定的权重指标的 可持续发展指数排名下广州、深圳都处于较高的可持续发展水平, 西安、哈 尔滨处于较低的可持续发展水平，并且整体上呈现南方的可持续发展水平高 于北方的可持续发展水平的趋势。

\subsection{2. 可持续发展的时间演变分析}

如表 3、表 4 所示, 就发展的均值来看, 2013 到 2017 年间, 所有副省级 城市的综合发展水平处于一个先升高后下降的一个趋势, 首先, 在 2014 年, 变异系数与公共参与确定的发展指数指标体系的平均值都达到一个峰值, 而 后均出现一个下降的趋势, 据分析, 可能是时任总书记的习近平同志提倡 “绿 水青山就是金山银山” 的结果, 一些副省级城市实现新旧动能转换, 导致第 二产业增加值等指标下降, 而这些指标在指标评价体系中占有重要的权重, 因此，在此期间，会出现一段时间内可持续发展指数的下降。

\subsection{3. 可持续发展的经济、社会、环境构成分析}

如表 5、表 6 所示, 在经济、社会、环境三个一级指标间的对比上, 各 年与两种方法间均呈现出经济发展水平与环境发展水平两个一级指标得分较 高, 而社会发展水平得分较低的情况。这表明, 总体来看, 中国副省级城市 的经济发展水平和环境发展水平总体较高, 而社会发展水平普遍较低。究其 


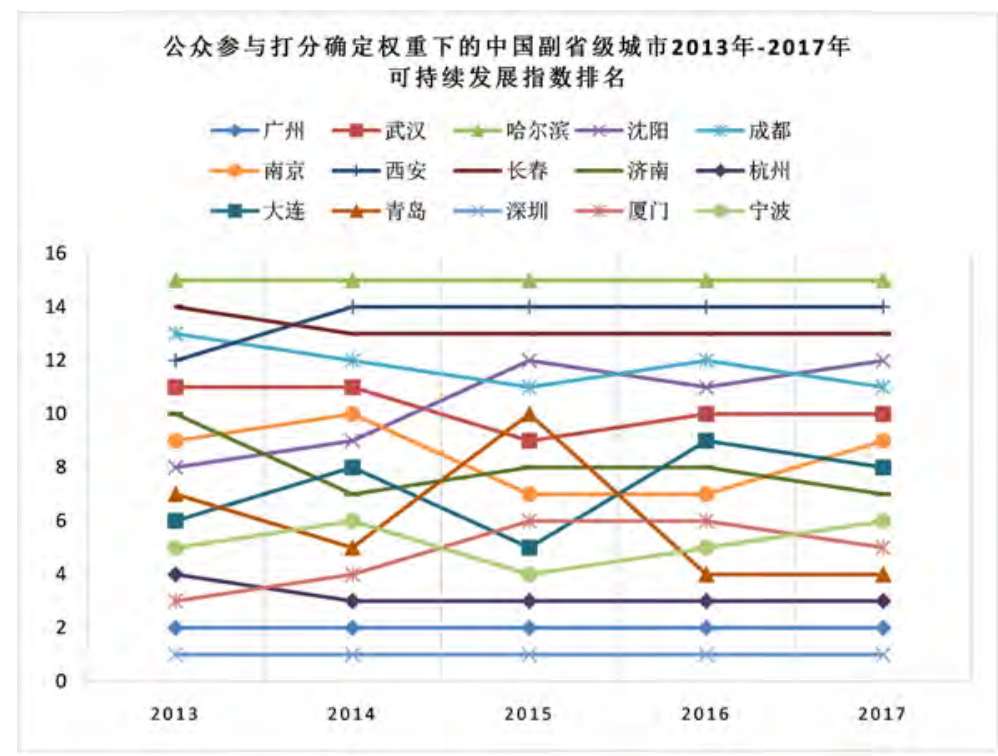

图 1. 公众参与打分确定权重下中国副省级城市 2013 年 2017年可持续发 展指数排名

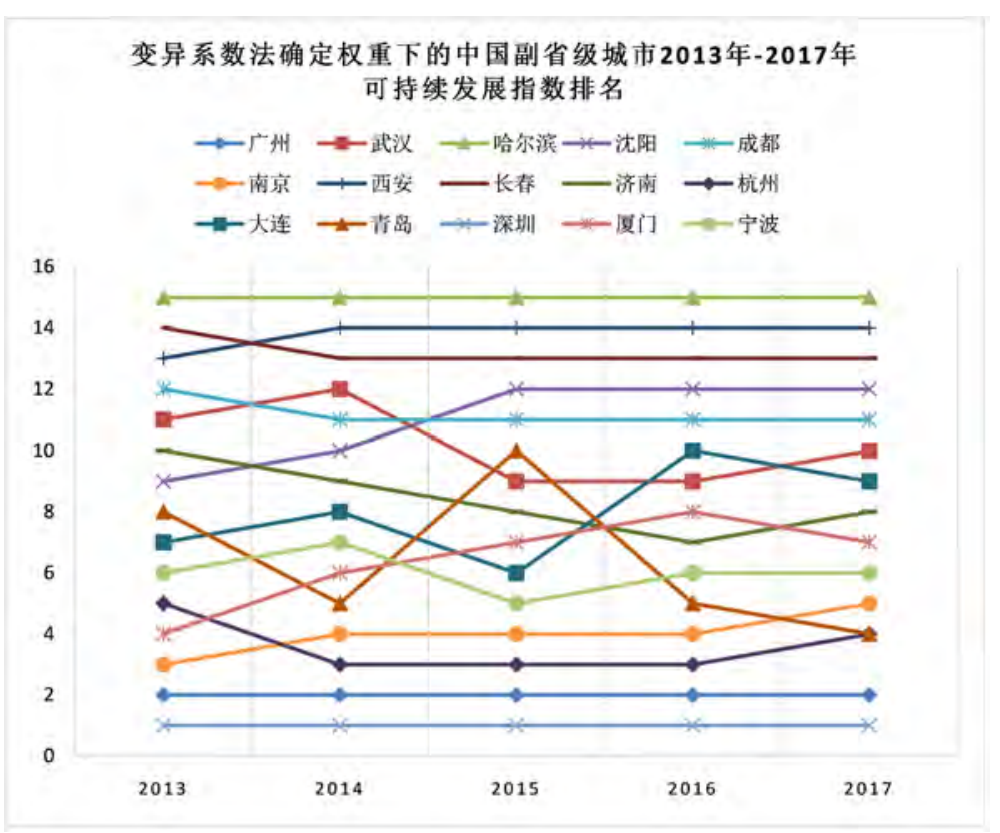

图 2. 变异系数确定权重下中国副省级城市 2013 年 2017 年可持续发展指 数排名

表 3. 公众参与打分确定权重下中国副省级城市 2013 2017 年可持续发展中可持续发 展指数

\begin{tabular}{cccccc}
\hline \multicolumn{5}{c}{ 公众参与打分确定权重下的中国副省级城市 $\mathbf{2 0 1 3}$ 年 2017 年可持续发展指数 } \\
\hline 广州 & 0.607795 & 0.698665 & 0.707667 & 0.740863 & 0.683941 \\
武汉 & 0.457134 & 0.456974 & 0.485272 & 0.455965 & 0.420425 \\
哈尔滨 & 0.221311 & 0.202566 & 0.232664 & 0.242292 & 0.220622 \\
沈阳 & 0.396371 & 0.392181 & 0.419257 & 0.487333 & 0.483785 \\
\hline
\end{tabular}




\begin{tabular}{cccccc} 
Continued & \multicolumn{1}{c}{} & & & \\
\hline 成都 & $\mathbf{0 . 4 0 0 5 7 1}$ & $\mathbf{0 . 3 7 7 2 5 7}$ & $\mathbf{0 . 4 5 3 8 6 8}$ & $\mathbf{0 . 4 4 9 0 7}$ & $\mathbf{0 . 3 3 7 5 3 4}$ \\
南京 & 0.465862 & 0.48735 & 0.524884 & 0.475814 & 0.47262 \\
西安 & 0.321167 & 0.272057 & 0.353956 & 0.325473 & 0.348566 \\
长春 & 0.352243 & 0.31494 & 0.392749 & 0.409504 & 0.276729 \\
济南 & 0.487282 & 0.477594 & 0.515636 & 0.519152 & 0.434388 \\
杭州 & 0.587008 & 0.574794 & 0.626464 & 0.617931 & 0.55347 \\
大连 & 0.468038 & 0.469443 & 0.567863 & 0.501191 & 0.502308 \\
青岛 & 0.562253 & 0.537407 & 0.47097 & 0.565335 & 0.497917 \\
深圳 & 0.789316 & 0.792912 & 0.78269 & 0.777002 & 0.838706 \\
厦门 & 0.534337 & 0.508338 & 0.555655 & 0.576093 & 0.597674 \\
宁波 & 0.50698 & 0.51039 & 0.59227 & 0.55048 & 0.538178 \\
\hline
\end{tabular}

表 4. 变异系数法确定权重下中国副省级城市 2013 2017 年可持续发展中可持续发展 指数

\begin{tabular}{cccccc}
\hline \multicolumn{5}{c}{ 变异系数法确定权重下的中国副省级城市 $\mathbf{2 0 1 3}$ 年 2017 年可持续发展指数 } \\
\hline 广州 & 0.589738 & 0.69671 & 0.726757 & 0.748596 & 0.613312 \\
武汉 & 0.331169 & 0.363719 & 0.386879 & 0.368883 & 0.287471 \\
哈尔滨 & 0.146986 & 0.1431 & 0.16409 & 0.172375 & 0.132355 \\
沈阳 & 0.262399 & 0.280986 & 0.339319 & 0.409163 & 0.334886 \\
成都 & 0.327875 & 0.31108 & 0.360291 & 0.369763 & 0.236446 \\
南京 & 0.407727 & 0.490718 & 0.520549 & 0.473638 & 0.435975 \\
西安 & 0.221625 & 0.193193 & 0.247296 & 0.244082 & 0.221202 \\
长春 & 0.241433 & 0.229583 & 0.276458 & 0.316508 & 0.187597 \\
济南 & 0.361463 & 0.390662 & 0.418774 & 0.423295 & 0.322917 \\
杭州 & 0.474523 & 0.492355 & 0.532614 & 0.517723 & 0.405131 \\
大连 & 0.344896 & 0.361697 & 0.456173 & 0.434575 & 0.367707 \\
青岛 & 0.481611 & 0.469961 & 0.363373 & 0.456253 & 0.340181 \\
深圳 & 0.736417 & 0.741487 & 0.767902 & 0.785187 & 0.845768 \\
厦门 & 0.370719 & 0.387337 & 0.42013 & 0.452474 & 0.418083 \\
宁波 & 0.378933 & 0.415965 & 0.490972 & 0.449345 & 0.384042 \\
\hline
\end{tabular}

表 5. 公众参与打分确定权重下的中国副省级城市 2013 2017 年可持续发展中各一级 指标均值

\begin{tabular}{cccccc}
\hline \multicolumn{2}{c}{ 公众参与打分确定权重下的中国副省级城市 2013 年 2017 年可持续发展中各一级指标均值 } \\
\hline & 2017 & 2016 & 2015 & 2014 & 2013 \\
\hline 经济 & 0.439028 & 0.421915 & 0.453278 & 0.455668 & 0.467285 \\
社会 & 0.38382 & 0.38625 & 0.457707 & 0.508759 & 0.382204 \\
环境 & 0.595573 & 0.592649 & 0.613324 & 0.566983 & 0.581342 \\
\hline
\end{tabular}


表 6. 公众参与打分确定权重下的中国副省级城市 2013 2017 年可持续发展中各一级 指标均值

\begin{tabular}{cccccc}
\hline \multicolumn{5}{c}{ 变异系数法确定权重下的中国副省级城市 2013 年 2017 年可持续发展中各一级指标均值 } \\
\hline & 2017 & 2016 & 2015 & 2014 & 2013 \\
\hline 经济 & 0.435214 & 0.41505 & 0.449873 & 0.454341 & 0.463136 \\
社会 & 0.292288 & 0.355702 & 0.417206 & 0.455917 & 0.276706 \\
环境 & 0.444477 & 0.431051 & 0.428391 & 0.417954 & 0.42146 \\
\hline
\end{tabular}

原因, 一方面可能是因为在指标选取上疏漏了衡量社会的教育、医疗、民生、 基础设施、科技等发展的指标, 另一方面也确实说明中国的副省级城市普遍 在社会发展上存在短板。今后副省级城市的发展应当更在注重城市发展的社 会发展方面。

在三个一级指标的年际变化方面, 两种方法均显示出了从 2013 年至 2015 年经济方面总体平稳发展、社会方面先上升后下降、环境方面波动发展的趋 势。这表明中国副省级城市的经济始终保持平稳, 而社会发展在一段时间的 提高后又重新衰退, 而环境则一直处于波动较大的状态。

在两种方法的对比上, 公众参与方法的环境指标得分较变异系数法高, 而较高的权重也使得环境指标在五年间的波动被放大, 其数值的波动程度大 于变异系数法下的环境指标的数值。此外, 公众参与下的社会发展水平也要 普遍高于变异系数法下的社会发展水平。而两种方法的经济指标则差异不大。 这表明, 在副省级城市的可持续发展中, 在社会和环境方面, 城市迎合了公 众所关注的方面, 城市对于公众所更为关注的社会和环境指标给予了足够的 重视，其发展在一定程度上符合公众对可持续发展的期望。

\section{2. 可持续发展的驱动因素分析}

进行地理探测器的因子探测分析需要首先对数据进行离散化处理, 本次 研究使用 SPSS 软件采用系统聚类的方式将每个指标的数据分类 4 类, 来进 行离散化处理。之后, 编写 Python 程序, 将分类后结果导入程序中, 得到影 响因子 $q$ 。

在参照其他文件资料的基础上, 主要依据各指标在公众参与打分确定的 权重大小, 选取当中权重较大的指标, 并综合考虑了指标之间的相互关系、 系统聚类效果和指标本身的含义, 最终选取了六个指标, 对其近三年的数据 进行驱动因素分析研究。六个指标为: 人均地区生产总值、第三产业增加值 占生产总值的比重、全年城市居民可支配收入、居民消费水平、市辖区绿地 面积和环境空气质量达标天数。表 7 表 8 表示为选取的六个指标 2015 年至 2017 年的可持续发展水平的因子探测结果。

就各指标间差异来讲, 人均地区生产总值在各年间无论在公众参与还是 变异系数法中, 均较大, 其中在 2016 年和 2017 年为各指标间最大。指标间 差异最大的其次为居民消费水平, 而居民消费水平这一指标虽为社会发展评 价指标, 但其指标本身又与城市的经济发展密不可分。除这二者外, 其余指 标得分均较小, 即对城市可持续发展的影响力较弱。上述结果说明对中国副 
表 7. 公共参与确定权重下 2015 2017 年全国副省级城市可持续发展因素

\begin{tabular}{cccccccc}
\hline \multicolumn{2}{c}{$\begin{array}{c}\text { 人均地区生产第三产业增加 } \\
\text { 总值/元 } \\
\text { 值占生产总埴 } \\
\text { 的比重/\% }\end{array} / \begin{array}{c}\text { 人均可支配 } \\
\text { 收入/元 }\end{array}$} & $\begin{array}{c}\text { 居民消费 } \\
\text { 水平/元 }\end{array}$ & $\begin{array}{c}\text { 市辖区绿地面 } \\
\text { 积 } / \mathrm{khm}^{2}\end{array}$ & $\begin{array}{c}\text { 境空气质量 } \\
\text { 达标天数 }\end{array}$ \\
\hline 2017 & 0.815140936 & 0.124014785 & 0.434633525 & 0.713434725 & 0.319876397 & 0.405534243 \\
2016 & 0.88382352 & 0.203917592 & 0.750550346 & 0.808191836 & 0.415248138 & 0.287385174 \\
2015 & 0.672646706 & 0.168022803 & 0.746725959 & 0.821204475 & 0.363858302 & 0.457393863 \\
\hline
\end{tabular}

表 8. 变异系数确定权重下 2015 2017 年全国副省级城市可持续发展因素

\begin{tabular}{|c|c|c|c|c|c|c|}
\hline & $\begin{array}{c}\text { 人均地区生产 } \\
\text { 总值/元 }\end{array}$ & $\begin{array}{c}\text { 第三产业增加 } \\
\text { 值占生产总值 } \\
\text { 的比重/\% }\end{array}$ & $\begin{array}{c}\text { 全年城市居民 } \\
\text { 人均可支配 } \\
\text { 收入/元 }\end{array}$ & $\begin{array}{c}\text { 居民消费 } \\
\text { 水平/元 }\end{array}$ & $\begin{array}{c}\text { 市辖区绿地面 } \\
\text { 积 } / \mathrm{khm}^{2}\end{array}$ & $\begin{array}{c}\text { 环境空气质量 } \\
\text { 达标天数 }\end{array}$ \\
\hline 2017 & 0.885325013 & 0.203172629 & 0.398124484 & 0.775013907 & 0.525779478 & 0.331016638 \\
\hline 2016 & 0.9179910914 & 0.28989571 & 0.799179341 & 0.767833577 & 0.589492898 & 0.221772596 \\
\hline 2015 & 0.791140195 & 0.283069067 & 0.84840933 & 0.798316839 & 0.593317515 & 0.430792285 \\
\hline
\end{tabular}

省级城市可持续发展水平影响力最大的是人均地区生产总值, 其次为居民消 费水平, 这两者均与地区经济发展密切相关, 表明了中国副省级城市的可持 续发展水平的高低本质上仍依赖于城市的经济发展，而非社会发展与环境发 展。

值得注意的是，在可持续发展得分的构成中，副省级城市的环境发展的 得分普遍较高, 且对于公众参与确定的权重而言, 环境发展项的权重也较大, 但却仍然不能成为可持续发展水平的最强影响因素。因子探测的结果表明, 环境发展水平的高低与可持续发展水平的高低在空间上的相关关系较弱, 环 境发展水平的分布更趋向于随机分布，而非接近可持续发展水平高的区域分 布, 即可持续发展水平高的城市, 其环境发展水平不一定高。相反, 经济发 展水平的高低反而与城市可持续发展水平高低在空间上呈强的相关关系, 即 可持续发展水平高的城市, 其经济发展水平一般较高。这表明, 中国副省级 城市在可持续发展过程中, 普遍存在经济发展与环境发展不协调的情况, 环 境发展并不能成为推动城市可持续发展的推动力, 经济发展水平高的城市的 环境状况也不一定与经济相适应, 环境更多地取决于城市各自的独特情况, 而非城市的发展水平。因而, 今后中国副省级城市的可持续发展必须要注重 在经济发展的同时协调城市环境的发展。

\section{5. 总结与讨论}

\section{1. 中国副省级城市可持续发展状况}

总体而言, 中国副省级城市的可持续发展情况不一, 但无论是在变异系 数确定的可持续发展评价体系还是公众视角下确定的可持续发展评价体系下， 广州、深圳都处于较高的可持续发展水平, 西安、哈尔滨处于较低的可持续 发展水平, 并且整体上呈现南方的可持续发展水平高于北方的可持续发展水 平的趋势。 


\section{2. 意见与建议}

建议: 从可持续发展的水平来看, 短期内, 南方可持续发展水平高于北 方可持续发展水平的格局很难改变, 所以, 我们在发展的过程中, 不要妄图 通过加大对北方副省级城市的投资来突破这一宕境, 在笔者看来, 首先, 北 方的副省级城市大多处于城市新旧动能转换阶段, 政府可以适当增加对新旧 动能转换的投资, 另外, 对于北方的副省级城市而言, 提高自己的城市等级 是提高自己可持续发展水平的重要方式, 例如哈尔滨提高自己对俄罗斯的辐 射能力, 长春提高自己对朝鲜的辐射能力, 而青岛提高对韩国的辐射能力等, 另外, 对南方的副省级城市而言, 首要的是要保证自己的城市发展水平, 另 外, 南方副省级城市可以增加自己对北方副省级城市的援助, 如利用北方地 价较南方低的情况实现多工厂的建设。

\section{3. 研究中存在的不足与创新}

指标的选取: 指标根据很多相关的论文[14] [15]得出, 具有一定的科学性, 但是由于相关性的论文数量丰富, 其他文章涉及的一些与可持续发展相关的 指标并未采纳, 存在某些城市的指标高就能在一定程度上影响可持续发展排 名的情况, 同时可能引发学界的讨论。

调查问卷: 根据所选取的指标设置调查问卷, 并且每个指标给予足够的 评分项(1: 影响力弱, 2: 影响力较弱, 3: 影响力中等, 4: 影响力较强, 5, 影响力强), 调查问卷符合设计需求, 但是参与人员中在校生评价比例偏高, 虽说满足调查问卷人员的参与要求, 但是仍然存在较大的偶然性, 并且在分 发的过程中存在非研究区域人员的参与问题, 外部的主观意向影响了内部的 相关因素的权重。

方法创新：提出一种用变异系数去验证辅助公民打分的方法, 在目前几 乎所有的论文中实属一种创新的办法。

\section{Conflicts of Interest}

The authors declare no conflicts of interest regarding the publication of this paper.

\section{References}

[1] 牛振国, 孙桂风. 近 10 年中国可持续发展研究进展与分析[J]. 中国人口.资源与 环境, 2007, 17(3): 122-128.

[2] 关进平, 余济云, 郭霞, 沈金明, 李俊, 胡焕香. 昌化江流域生态经济可持续发展 评价[J]. 中南林业科技大学学报, 2012, 32(3): 89-93.

[3] 张婧, 李强, 周汫. 陕西省城市可持续发展评价[J]. 中国人口. 资源与环境, 2013, 23(S2): 448-453.

[4] 刘志成, 刘晗. 湖南省资源型城市可持续发展能力评价一一基于生态足迹模型的 视角 [J]. 长沙理工大学学报(社会科学版), 2020, 35(3): 96-103.

[5] 邓锦山, 向晓宇, 丁鹏凯, 郡怀勇. 基于能值分析的绵阳市城市生态经济系统健 康评价[J]. 湖北农业科学, 2020, 59(3): 158-164+169.

[6] 赵海云, 李仲学, 张以诚. 矿业城市的可持续发展指标体系研究和可持续发展水 
平评价[J]. 中国矿业, 2004(12): 18-23+39.

[7] 周子英, 向昌盛, 米振华. 长株潭城市群都市农业可持续发展综合评价[J]. 水土 保持通报, 2019, 39(5): 278-284.

[8] 李博, 乔慧玲, 杨子涵. 环渤海地区资源型城市可持续发展能力评价研究 [J]. 湖 北师范大学学报(哲学社会科学版), 2019, 39(6): 72-83.

[9] 霍丽娜. 资源型城市可持续发展水平综合评价研究——以榆林市为例[J]. 科技通 报, 2019, 35(11): 177-181.

[10] 许学强, 张俊军. 广州城市可持续发展的综合评价[J]. 地理学报, 2001(1): 54-63.

[11] 关伟, 刘勇风. 辽宁沿海经济带经济与环境协调发展度的时空演变[J]. 地理研究, 2012, 31(11): 2044-2054.

[12] 孙黄平, 黄震方, 徐冬冬, 施雪荣, 刘欢, 谭林胶, 葛军莲. 泛长三角城市群城镇 化与生态环境耦合的空间特征与驱动机制 [J]. 经济地理, 2017, 37(2): 163-170+186.

[13] 王劲峰, 徐成东. 地理探测器: 原理与展望[J]. 地理学报, 2017, 72(1): 116-134.

[14] 阚子翔, 赵庚星. 山东半岛蓝色经济区城市可持续发展评价 [J]. 可持续发展, 2019, 9(3): 458-466.

[15] 赵丹丹, 高世葵. 基于 AHP 的资源型城市可持续发展水平评价研究一一以山西 省为例 [J]. 资源与产业, 2015, 17(5): 1-7. 


\section{附录一：调查问卷内容}

问卷题目：公众参与的可持续发展评价指标打分

前言：可持续发展包含两层含义，一是可持续，二是发展。不能因为要 发展而放弃可持续, 也不能因为要可持续, 而放弃发展。当然, 二者更应该 侧重哪一方面, 正是本份问卷需要您判断的。问卷各问题是对某一区域的可 持续发展的评价指标, 请为这些指标的重要程度打分，从 1 分到 5 分表明该 指标的重要程度逐渐增大, 如果您认为该指标对于可持续发展非常重要, 请 打 5 分, 如果您认为该项指标对于可持续发展基本不相关，则打 1 分。请注 意, 可持续发展, 既要评价其环境怎么样, 也要评价其经济社会发展水平, 二者是并行的。(注意, 本次调查问卷调查范围主要针对在读高校以及职业学 校学生以及社会从业人员, 其他人等请勿填写, 涉及到个人隐私部分调查问 卷不会泄露, 否则愿意承担一切法律责任)

问卷打分部分:

1 , 人均地区生产总值（地区经济发展评价）
1 ( )
2()
3()
4 ( )
5()

2, 第三产业增加值占生产总值的比重（地区经济发展评价）
1 ( )
2()
3()
4 ()
5()

3, 第二产业增加值占生产总值的比重（地区经济发展评价）
1 ( )
2()
3()
4()
5()

4 , 人均工业增加值（地区经济发展评价）
1 ( )
2()
3()
4 ( )

5 , 全年城镇居民可支配收入（地区社会发展评价）
1()
2()
3 ( )
4 ( )
5()

6, 居民消费水平（地区社会发展评价）
1 ( )
2 ()
3()
4 ( )
5()

7 , 全市新增就业人数（地区社会发展评价）
1 ( )
2()
3()
4 ( )
5()

8 , 图书馆藏书量（地区社会发展评价）
1 ( )
2()
3()
4()
5()

9, 市辖区绿地面积（地区环境评价）
1 ( )
2()
3()
4 ()
5()

10 , 环境空气质量达标天数 (地区环境评价)
1 ( )
2 ()
3()
4()
5()

11, 城市污水集中处理率（地区环境评价）
1 ( )
2 ()
3()
4 ( )

12, 无害化垃圾处理率（地区环境评价）
1 ( )
2 ()
3()
4()
5()

13 , 您的性别

男( ) 女( )

14 , 您的职业是 ()

在校生( ) 社会从业人员( ) 
15 , 您的年龄

18 28 岁 () 28 38 岁 ( ) 38 48 岁( ) 48 55 岁( )

\section{附录二: 调查问卷信度与效度说明}

利用 SPSS 软件, 对所获得的 12 个指标的样本进行分析, 最终结果如下:

信度分析:

\begin{tabular}{ccc}
\hline \multicolumn{3}{c}{ 可靠性统计量 } \\
\hline Cronbach's Alpha & 基于标准化项的 Cronbachs Alpha & 项数 \\
\hline .944 & .945 & 12 \\
\hline
\end{tabular}

笔者利用 SPSS 测出样本的 Cronbach $\alpha$ (克隆巴赫)系数为 $0.944,0.944>$ 0.9 , 说明笔者做制作的调查问卷的信度高。

\section{效度分析:}

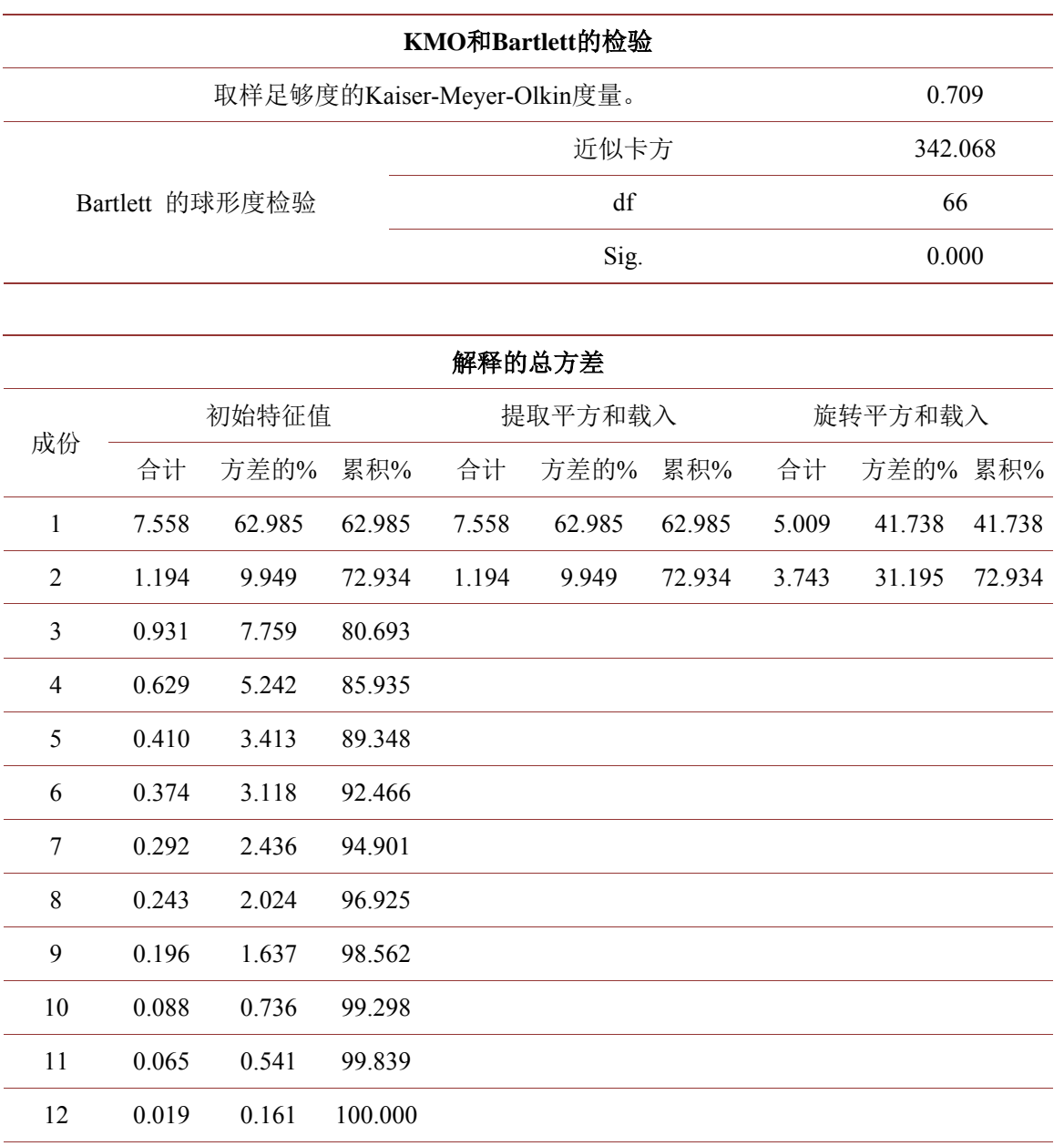

提取方法: 主成份分析。

$\mathrm{KMO}$ 值为 $0.709>0.6$ 通过巴特球形检验, 旋转后累计方差解释率为 $72.934 \%>50 \%$, 综合说明研究数据具有良好的结构效度水平。 